\title{
UJI VISUAL TEMOGRAFI PADA OSCILLATING HEAT PIPE
}

\author{
Adi Winarta ${ }^{1}$, Ida Bagus Putu Sukadana ${ }^{2 *}$, Nandy Putra ${ }^{3}$, I Wayan Suastawa ${ }^{4}$, I Wayan Suirya ${ }^{5}$ \\ 1,2,4,5 Jurusan Teknik Mesin, Politeknik Negeri Bali, Kampus Bukit Jimbaran, Badung-Bali \\ ${ }^{1,3}$ Lab AHTRG, Jurusan Teknik Mesin, Fakultas Teknik, Universitas Indonesia, Kampus Baru Depok \\ E-mail: ${ }^{1}$ winarta.adi@mail.com, ${ }^{2}$ bagusputusukadana@pnb.ac.id, ${ }^{3}$ nandyputra@eng.ui.ac.id, \\ 4asta782002@yahoo.com
}

\begin{abstract}
Abstrak
Abstrak-- Oscillating Heat Pipe (OHP) merupakan salah satu varian terbaru dari teknologi heat pipe atau pipa kalor. Teknologi transfer kalor dua fase (heat pipe) ini diprediksi mempunyai kemampuan kinerja yang sangat baik, struktur sederhana dan biaya produksi rendah. Sebagai salah satu metode non-intrusif dalam pengukuran suhu, pengamatan termografi pada OHP masih sangat jarang digunakan meskipun hasilnya mampu menjelaskan hubungan antara temperatur dan gerakan fluida fluida. Pada studi ini dilakukan penelitian untuk mengamati perilaku profil termal menggunakan metode termografi. Sebuah OHP dengan fluida kerja air dan filing ratio (45\%) diuji dengan beban kalor yang bervariasi pada bagian evaporator. Daya heater pada OHP diberikan dari 12 hingga 142 Watt. Hasil menunjukkan bahwa termografi merupakan alat yang sangat efektif untuk mengamati pola aliran internal dalam saluran OHP. Gerakan osilasi berkala dan sirkulasi diamati dengan baik oleh metode ini. Hambatan termal terendah didapatkan sebesar $0,234^{\circ} \mathrm{C} / \mathrm{W}$ pada daya heater 142 Watt.
\end{abstract}

Kata Kunci: Oscilating Heat Pipe, termografi, flow regime, performa termal

\begin{abstract}
Oscillating Heat Pipes one of the new family of heat pipe is two-phase heat transfer technologies with excellent performance, simple structure and low production costs. As one of the non-intrusive method in temperature measurement, thermography observation in OHP still very rarely to use although the result is able to explain the relation between temperature oscillation and fluidic motion of fluid. this paper aims to study the behavior of thermal profile with the thermography observation. Water with filing ratio (45\%) has chosen as the working fluid for the close loop OHP. The heating power was varying into the evaporator section of OHP from 12 until 142 Watt. It was found that thermography observation is very useful tools to define internal flow pattern inside OHP channel. Intermittent oscillation, circulation and dry-out phenomenon were captured more better than conventional temperature measurement. The lowest thermal resistance was found $0.234{ }^{\circ} \mathrm{C} / \mathrm{W}$ corresponding with $3210 \mathrm{Watt} / \mathrm{mK}$ effective thermal conductivity at heat input 142 Watt.
\end{abstract}

Keywords: Oscillating Heat Pipe, Thermography, Flow Regime, Thermal Performances

\section{PENDAHULUAN}

Oscillating Heat Pipe (OHP) sebagai salah satu teknologi transfer kalor dua fasa terbaru telah menarik perhatian banyak ilmuwan diseluruh dunia dalam dua dekade terakhir ini. OHP yang merupakan salah satu jenis varian pipa kalor (heat pipe) ditengarai memiliki kemampuan kinerja yang sangat baik, struktur sederhana dan biaya produksi yang sangat rendah. Hal ini yang membuat OHP memberikan potensi besar dalam berbagai aplikasi perpindahan kalor yang efektif, efisien dan ringkas 
(X. Han, X. Wang, H. Zheng, X. Xu, 2016; Y. Zhang and A. Faghri, 2008).

Teknologi ini pertama kali diperkenalkan oleh Akachi et al. (Smyrnov, 2003) pada USA Patent pada 1990. Meskipun konsep dasar OHP sebenarnya telah diusulkan oleh Smyrnov dan Savchenkov di Russia dengan Patent pada tahun 1975 (G, 1975). Akan tetapi, penelitian-penelitian yang berkembang akhirakhir ini menggunakan konsep struktur yang diberikan oleh H. Akachi. Smirnov kembali mematenkan metode, konstruksi dan konsep dasar heat pipe jenis ini (Smyrnov, 2003) pada organisasi paten di Amerika Serikat, ditahun 2003.

Prinsip kerja OHP pada dasarnya adalah transfer kalor dari bagian evaporator ke bagian kondensor akibat osilasi atau sirkulasi dari fluida kerja (di dalam OHP). Osilasi atau sirkulasi cairan kerja ini disebabkan oleh perbedaan tekanan pada evaporator dan kondenser. Ini terjadi karena adanya kalor masuk di bagian evaporator dan pelepasan kalor pada kondenser. Masukan kalor pada evaporator akan menciptakan pertumbuhan gelembung (bubble) dan secara bersamaan, kalor yang dilepas pada kondenser akan menghasilkan kondensasi bubble. Kondisi ini menghasilkan gerakan distribusi fluida kerja dalam bentuk komposisi cairan dan uap, akan menyebabkan thermohidrodinamika yang kompleks dalam bentuk gerakan berdenyut dan osilasi (Tong, Wong, \& Ooi, 2001).

Penelitian OHP dalam dekade terakhir difokuskan pada beberapa aspek, seperti pola aliran cairan kerja, kinerja termal, orientasi global, efek gravitasi dan analisis matematika (Charoensawan \& Terdtoon, 2008; S Khandekar, Schneider, \& Groll, 2002; S Khandekar, Schneider, Schafer, Kulenovic, \& Groll, 2002; Sameer Khandekar, Charoensawan, Groll, \& Terdtoon, 2003; Kim, Bui, Kim, Kim, \& Jung, 2003; Tong et al., 2001; X. Han, X. Wang, H. Zheng, X. Xu, 2016; Yang, Khandekar, \& Groll, 2009). Hasil beberapa studi pola aliran, diketahui beberapa pola seperti aliran gelembung, aliran slugflow, annular dan semi annular terjadi selama proses operasional (S Khandekar, Schneider, Schafer, et al., 2002; Sameer Khandekar et al., 2003). Setiap pola memiliki karakteristik perpindahan kalor yang berbeda yang selanjutnya akan mempengaruhi kinerja OHP (Wilson et al., 2011). Sebagai salah satu parameter utama, suplai kalor ke evaporator sangat mempengaruhi pola aliran dan berkontribusi pada gerakan osilasi pada pola aliran slug-flow didalam OHP. Pola aliran yang berbeda menyebabkan potensi perpindahan kalor yang berbeda. Ketika suplai kalor meningkat, kemampuan transfer kalor juga akan meningkat sebagai akibat dari gerakan osilasi (Ma, 2015). Pengamatan pola aliran seperti osilasi, sirkulasi, perubahan arah aliran dan aliran searah sirkulasi ini sangat erat kaitannya dengan perubahan suplai kalor (Borkar \& Pachghare, 2014). Pada studi ini dilakukan penelitian untuk mengamati perilaku profil termal menggunakan metode termografi (kamera infra red).

\section{METODE}

Observasi visualisasi pada OHP biasanya menggunakan material dengan tabung transparan. Namun, penggunaan bahan-bahan ini memiliki beberapa kelemahan seperti suhu transien yang akan sulit dikenali karena konduktivitas termalnya yang rendah (Thompson, Ma, Winholtz, \& Wilson, 2009). Karthikeyan (Karthikeyan, Khandekar, Pillai, \& Sharma, 2014) melakukan pengamatan dengan teknik termografi untuk profil termal fluida kerja OHP untuk mendapatkan hubungan kinerja termal dengan karakter pola aliran. dalam penelitian tersebut, digunakan air sebagai fluida kerja dengan rasio pengisian $60 \%$ dan OHP memiliki 10 putaran. Hasil penelitian tersebut menunjukkan bahwa termografi inframerah adalah alat yang sangat sesuai untuk digunakan dalam mengamati kondisi perpindahan panas transien seperti OHP. Sebagai salah satu metode non-intrusif dalam pengukuran suhu, pengamatan termografi dalam OHP masih sangat jarang digunakan meskipun hasilnya mampu menjelaskan hubungan antara osilasi suhu dan fluidic motion of fluid. Dalam penelitian ini, rasio pengarsipan $(45 \%)$ dari OHP dengan air sebagai fluida kerja diamati dengan teknik termografi untuk menggambarkan regim aliran dan hubungan kinerja termal.

Geometri OHP dibuat menggunakan pipa kapiler dengan diameter dalam dan luar masing-masing 1,6 dan 3,18 mm. Dimensi pipa kapiler dihitung menggunakan persamaan diameter kritis yang diturunkan dari persamaan Bond Number. Sepertinya yang diberikan pada persamaan dibawah berikut:

$d_{\max }=1.8 \times \sqrt{\left(\sigma /\left(\rho_{l}-\rho_{v}\right)\right)}$

Gambar 1 merupakan skematik uji karakteristik thermal OHP. Dimensi OHP adalah panjang dan lebar $230 \mathrm{~mm}$ x $110 \mathrm{~mm}$. Jumlah lekukan pada OHP ini sebanyak 10 buah. Pengamatan thermography dilakukan menggunakan kamera infrared portable (FLIR i50) hanya pada bagian adiabatik dari OHP. Untuk keperluan ini, pada bagian adiabatik, tidak dilakukan isolasi sebagaimana pengujian yang biasa dilakukan untuk menguji kinerja. Selain itu bagian adiabatik pipa kapiler OHP dicat dengan warna hitam. Kondisi ini juga disesuaikan dengan setting 
yang dilakukan pada kamera infrared (objek yang diamati diset mempunyai emisivitas "black body").

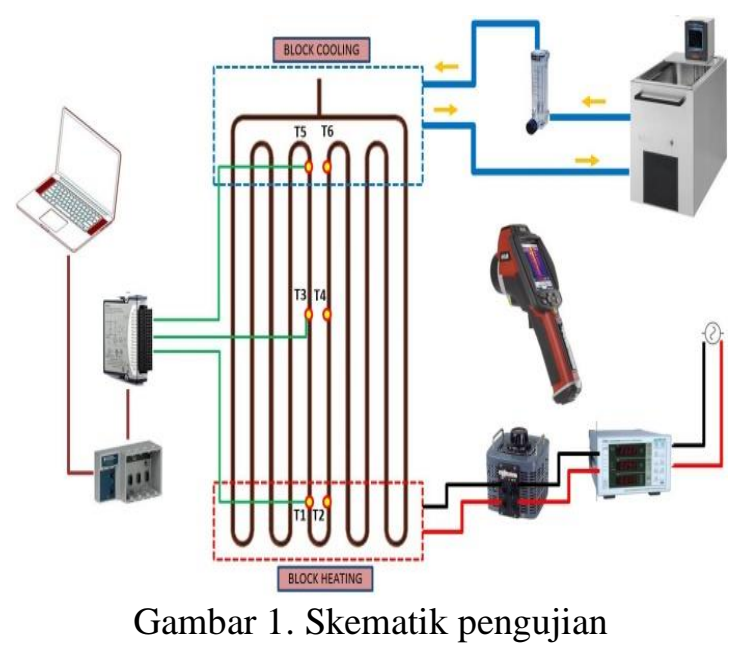

\section{HASIL DAN PEMBAHASAN}

Distribusi temperatur yang diamati oleh Karthikeyan et al. dengan teknik termografi dengan jelas menunjukkan bahwa ada pola aliran yang berbeda pada OHP (Karthikeyan et al., 2014). Dengan menggunakan kamera infra-red dan termokopel, pengujian ini bertujuan untuk mengamati distribusi suhu transien pada OHP dengan variasi suplai kalor (Q). Tanpa menggunakan teknik visualisasi sangat sulit untuk menentukan perilaku dinamis liquid slug dan vapor plug pada PHP/OHP. Gambar 4.2 menunjukkan pergerakan fluktuasi temperatur pada evaporator dan kondenser pada berbagai variasi suplai kalor (Q). Secara garis besar variasi suplai kalor dibagi menjadi dua bagian, yakni suplai 13-47 Watt dan suplai kalor 51-109 Watt. Tiap-tiap suplai kalor dianalisis pada masing-masing bagiannya untuk mendapatkan fenomena perpindahan kalor yang lebih mendetail.

Gambar 2, I $\mathrm{a}-\mathrm{h}$ menunjukkan grafik fluktuasi/osilasi temperatur evaporator dan kondenser pada suplai kalor dari 13 Watt sampai dengan 47 Watt. Grafik osilasi temperatur pada masing-masing suplai kalor dibandingkan dengan hasil thermography yang terkait. Pemanfaatan teknik themography pada saat pengujian dapat memudahkan pengamatan saat proses start-up mulai terjadi. Hal ini, dapat dilihat pada gambar 2 bagian I $\mathrm{a}$ dan $\mathrm{b}$ yang menunjukkan adanya rambatan kalor pada tiap-tiap channel/pipa yang berasal dari bagian evaporator. Panjang rambatan kalor (jejak thermal) tiap channel adalah sama dan seragam. Data temperatur thermokopel juga menunjukkan kenaikan yang linear Hal ini menunjukkan dengan jelas belum terdapat gerakan fluida pada OHP. Kenaikan suhu transien pada evaporator dan kondenser terjadi karena proses perpindahan kalor konduksi pada bagian solid pipa tembaga. Transfer kalor yang melibatkan aliran fluida kerja belum terlihat. Kalor yang disuplai oleh blok konduksi (heater) belum mampu menaikkan temperatur surface diatas temperatur saturasi fluida kerja (air). Sehingga pendidihan belum terjadi dan driving force yang diperlukan untuk menggerakan fluida kerja tidak terjadi. Karena terdapat beda temperatur antara bagian evaporator dan kondenser maka kalor dihantarkan melalui konduksi. Akibat lainnya terjadi rugi kalor (heat loss) pada bagian adiabatik.

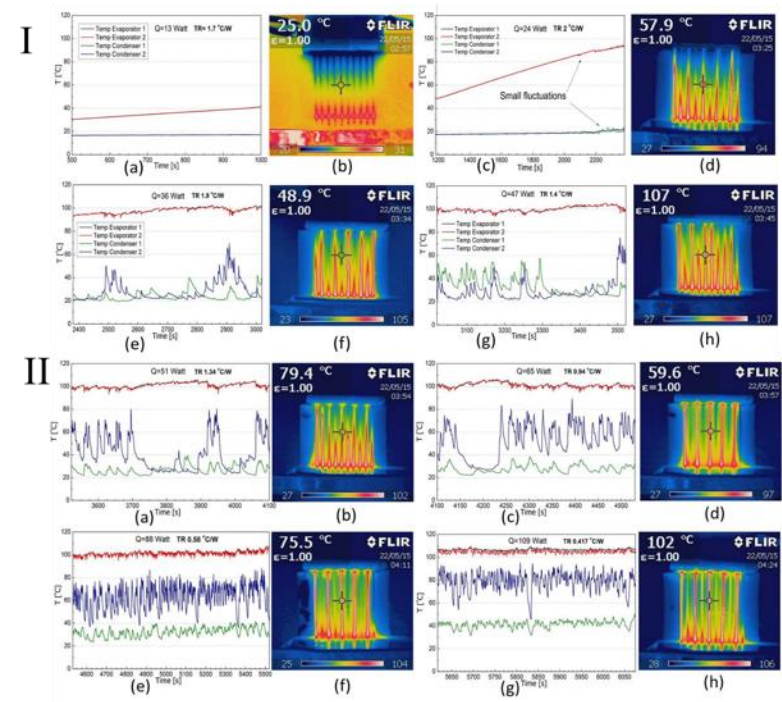

Gambar 2. Fluktuasi Temperatur pada PHP dan hubungannya dengan visual thermography, I a-h pada suplai kalor 13-47 Watt, II a-h 51-109 Watt.

Pada kalor suplai 24 Watt mulai terlihat fluktuasi temperatur yang masih kecil (Gambar 2 bagian I,c). Hal ini mengindikasikan mulai terbentuknya dispersed bubble/bubbly flow pada permukaan pipa kapiler bagian dalam. Akan tetapi, begitu lepas dari permukaan dinding bagian dalam pipa kapiler, bubble ini akan terkondensasi kembali. Karena temperatur lingkungannya yang masih lebih rendah dibandingkan "bubble"nya sendiri $\left(<100^{\circ} \mathrm{C}\right)$. Akibatnya timbulnya fluktuasi dengan amplitudo yang sangat kecil. Karena terjadinya pada pipa kapiler yang memiliki dimensi pada orde milimeter, maka akan muncul fluktuasi yang kecil pada hasil pengukuran.

Pada thermography terlihat panjang jejak thermal tiap channel mulai terlihat memiliki panjang yang berbeda (Gambar 1 I,d). Jejak thermal ini menunjukkan mulai terjadinya gerakan fluida kerja pada bagian adiabatik. Kenaikan suplai kalor berikutnya diperlihatkan pada gambar 4.7 bagian e 
dan f menunjukkan profil fluktuasi yang lebih meningkat. Fluktuasi temperatur pada evaporator dan kondenser ini menunjukkan pergerakan liquid slug dan vapour plug. Pada fasa ini transfer kalor dua phase yang terjadi menghasilkan pertumbuhan bubble pada suhu yang relatif konstan. Akibatnya, suhu evaporator cenderung steady dengan osilasi temperatur yang kecil. Sedangkan pada kondenser, osilasi temperatur tampak lebih kuat karena proses kondensasi yang terjadi akibat beda temperatur yang cukup tinggi antara bagian kondenser dan aliran air dingin yang sangat rendah dari CTB $\left(15^{\circ} \mathrm{C}\right)$. Proses transfer kalor laten menjadi lebih dominan pada bagian kondenser. Kenaikan suplai kalor berikutnya (47 Watt) meningkatkan osilasi temperatur yang terjadi (Gambar 2 I,g dan h). Oleh karena itu terjadi penurunan tahanan termal sebesar $26,3 \%$ pada suplai 36 ke 47Watt akibat terjadi gerakan fluida kerja.

Gambar 2 II a-h menunjukkan pergerakan temperatur akibat suplai kalor menengah. Berturutturut mulai 51 Watt, 65 Watt, 88,3 Watt dan 109 Watt. Gambar 2 IIa menunjukkan fluktuasi temperatur pada suplai kalor 51 Watt. Dari grafik dapat kita amati bahwa suhu evaporator cenderung stabil pada rata-rata $101,15^{\circ} \mathrm{C}$, yang mengindikasikan terjadi penyerapan kalor oleh pipa kalor secara dua fasa. Adanya fluktuasi temperatur pada evaporator dan kondenser juga mendukung fenomena ini. Fluktuasi dengan amplitudo yang lebih tinggi terjadi pada kondenser $\left(20-40^{\circ} \mathrm{C}\right)$. Fenomena ini menunjukkan pertukaran kalor yang makin intens pada kondenser akibat pergerakan hot slug didalam pipa kapiler. Fluktuasi temperatur pada evaporator jauh lebih rendah dibandingkan dengan fluktuasi pada bagian kondenser. Hasil thermography menunjukkan jejak thermal gerakan osilasi liquid slug dan vapor plug yang acak (random) pada Gambar 2 II,b.

Pada suplai kalor berikutnya yakni 65 Watt, frekuensi fluktuasi temperatur yang dihasilkan pada kondenser dan evaporator menjadi lebih kuat (gambar 2 II,c). Kenaikan suplai kalor memberikan energi yang cukup kuat untuk menaikkan momentum fluida kerja (liquid slug dan vapor plug) sehingga terjadi perubahan pola aliran osilasi yang sebelumnya masih acak ke aliran yang lebih teratur. Perubahan pola aliran ini juga menurunkan tahanan termal dari $1,34^{\circ} \mathrm{C} / \mathrm{W}$ ke $0,93{ }^{\circ} \mathrm{C} / \mathrm{W}$. Perubahan pola aliran sirkulasi fluida kerja meningkatkan kinerja perpindahan kalor pada OHP.

Fenomena yang terjadi pada Gambar $2 \mathrm{f}$ dan $\mathrm{h}$, juga mengindikasikan bahwa selama sirkulasi, liquid dan vapor slug juga mengalami osilasi secara aksial. Borkar et al (Borkar \& Pachghare, 2014) menyatakan bahwa definisi yang tepat untuk gerakan ini adalah "oscillatory circulation " atau sering dikatakan sebagai bulk circulation. Selama berosilasi terdapat berbagai frekuensi yang membuat fluida kerja bergerak tanpa beraturan. Gerakan "oscillatory circulation" fluida kerja ini juga memiliki kecenderungan arah yang berubah-ubah pada suplai kalor tertentu. Menaikkan suplai kalor menjadi 88 Watt mengakibatkan kenaikan fluktuasi temperatur pada evaporator dan kondenser (gambar 4.4e). Terjadi kenaikan temperatur rata-rata pada evaporator menjadi sekitar $102,2{ }^{\circ} \mathrm{C}$. Kenaikan ini, walaupun memberikan efek naiknya temperatur ratarata evaporator namun juga mengakibatkan penurunan tahanan termal. Pada suplai kalor 109 Watt, evaporator dan kondenser memiliki frekuensi fluktuasi temperatur yang tetap tinggi (gambar $4.4 \mathrm{~g}$ ). Temperatur rata-rata evaporator juga naik menjadi $106,6{ }^{\circ} \mathrm{C}$. Suhu rata-rata kondenser juga meningkat dari $34,2{ }^{\circ} \mathrm{C}$ menjadi $41,47{ }^{\circ} \mathrm{C}$ akibat kenaikan suplai kalor dari 88 Watt menjadi 109 Watt. Peningkatan suhu rata-rata dapat juga diamati pada distribusi jejak thermal pada gambar thermogrphy. Dari sudut pandang termal, seluruh permukaan OHP memiliki suhu yang lebih tinggi. Hal ini mengindikasikan kenaikan fraksi uap fluida kerja pada OHP secara keseluruhan.

\section{KESIMPULAN}

Sebuah Oscillating Heat Pipe (OHP) dengan bahan pipa kapiler tembaga telah dibuat dan diuji kinerja termalnya bersamaan dengan aliran jejak termalnya menggunakan metode thermography. Fluida kerja yang digunakan adalah DI Water dengan filling ratio sebesar $45 \%$. OHP memiliki 10 lekukan pada evaporator dan kondenser. Dari hasil pengujian yang telah dilakukan beberapa kesimpulan pokok diberikan sebagaimana dibawah berikut:

1) Pada suplai kalor rendah (4 dan 13 Watt), metode termografi berhasil mengamati perubahan warna di sekitar bagian adiabatik akibat rugi-rugi kalor yang terjadi pada bagian adiabatik. Rugi kalor (heat loss) terjadi akibat PHP pada suplai kalor rendah belum mampu melakukan transfer kalor dengan baik. Sehingga sebagian besar kalor yang masuk ke evaporator terbuang ke lingkungan yang menyebabkan naiknya temperatur lingkungan sekitar daerah adiabatik.

2) Beberapa lonjakan fluktuasi hot slug pada bagian adiabatik terekam secara termografi dan konsisten dengan data temperatur yang diperlihatkan pada termokopel. Hasil ini memberikan bukti bahwa pergerakan jejak 
temperatur (thermal footprints) menggunakan metode thermography mampu menunjukkan fluktuasi yang terjadi pada bagian adiabatik.

3) Pada beban daya awal (13 Watt), kalor yang disuplai oleh blok konduksi (heater) belum mampu menaikkan temperatur surface diatas temperatur saturasi fluida kerja (air). Sehingga pendidihan belum terjadi dan driving force yang diperlukan untuk menggerakan fluida kerja tidak terjadi. Hal ini ditunjukkan thermography berupa rambatan termal (thermal footprints) yang sama tinggi pada masing-masing kanal.

4) Pada termografi di suplai kalor 24 Watt terlihat panjang jejak termal tiap channel mulai terlihat memiliki panjang yang berbeda. Jejak termal ini menunjukkan mulai terjadinya gerakan fluida kerja pada bagian adiabatik.

5) Pada suplai kalor menengah (51 Watt) suhu evaporator cenderung stabil pada rata-rata $101,15^{\circ} \mathrm{C}$, yang mengindikasikan terjadi penyerapan kalor oleh pipa kalor secara dua fasa. Hasil termografi menunjukkan jejak termal gerakan osilasi liquid slug dan vapor plug yang acak (random).

\section{DAFTAR PUSTAKA}

Borkar, R., \& Pachghare, P. (2014). ThermoHydrodynamic Behavior of Methanol Charged Closed Loop Pulsating Heat Pipe. Frontiers in Heat Pipes (FHP), 5(1).

Charoensawan, P., \& Terdtoon, P. (2008). Thermal performance of horizontal closed-loop oscillating heat pipes. Applied Thermal Engineering, 28(5-6), 460-466.

G, S. G. S. (1975). No Title. USSR Patent.

Karthikeyan, V. K., Khandekar, S., Pillai, B. C., \& Sharma, P. K. (2014). Infrared thermography of a pulsating heat pipe: Flow regimes and multiple steady states. Applied Thermal Engineering, 62(2), 470-480.

Khandekar, S., Charoensawan, P., Groll, M., \& Terdtoon, P. (2003). Closed loop pulsating heat pipes Part B: visualization and semiempirical modeling. Applied Thermal Engineering, 23(16), 2021-2033.

Khandekar, S., Schneider, M., \& Groll, M. (2002). Mathematical modeling of pulsating heat pipes: state of the art and future challenges. Heat and Mass Transfer, SK Saha, SP Venkateshen, BVSSS Prasad, and SS Sadhal, Eds., Tata McGraw-Hill Publishing Company, New Delhi, India, 856-862.

Khandekar, S., Schneider, M., Schafer, P.,
Kulenovic, R., \& Groll, M. (2002). Thermofluid dynamic study of flat-plate closed-loop pulsating heat pipes. Microscale Thermophysical Engineering, 6(4), 303-317.

Kim, J.-S., Bui, N. H., Kim, J.-W., Kim, J.-H., \& Jung, H. S. (2003). Flow visualization of oscillation characteristics of liquid and vapor flow in the oscillating capillary tube heat pipe. KSME International Journal, 17(10), 15071519.

Ma, H. (2015). Oscillating heat pipes. Springer.

Smyrnov, G. (2003). Method of action of the pulsating heat pipe, its construction and the devices on its base. US Patent.

Thompson, S. M., Ma, H. B., Winholtz, R. A., \& Wilson, C. (2009). Experimental investigation of miniature three-dimensional flat-plate oscillating heat pipe. Journal of Heat Transfer, 131(4), 43210.

Tong, B. Y., Wong, T. N., \& Ooi, K. T. (2001). Closed-loop pulsating heat pipe. Applied Thermal Engineering, 21(18), 1845-1862.

Wilson, C., Borgmeyer, B., Winholtz, R. A., Ma, H. B., Jacobson, D., \& Hussey, D. (2011). Thermal and visual observation of water and acetone oscillating heat pipes. Journal of Heat Transfer, 133(6), 61502.

X. Han, X. Wang, H. Zheng, X. Xu, and G. C. (2016). Review of the development of pulsating heat pipe for heat dissipation. Renewable and Sustainable Energy Reviews, 59, 692-709.

Y. Zhang and A. Faghri. (2008). Advances and unsolved issues in pulsating heat pipes. Heat Transfer Engineering, 29, 20-44.

Yang, H., Khandekar, S., \& Groll, M. (2009). Performance characteristics of pulsating heat pipes as integral thermal spreaders. International Journal of Thermal Sciences, 48(4), 815-824. 